\title{
ANALYTICAL SURVEY OF WINDOWS OPERATING SYSTEM AND COMPARISON OF WINDOWS, LINUX AND ANDROID OPERATING SYSTEM
}

\author{
Ravikant Tiwari \\ B.Tech $2^{\text {nd }}$ year, \\ Department of Computer Science and \\ Engineering, \\ BBDITM, Lucknow \\ U.P. 206028, India,
}

\author{
Mr. Shadab Siddique \\ Associate Professor \\ Department of Computer Science and \\ Engineering, \\ BBDITM, Lucknow, \\ U.P. 206028, India
}

\begin{abstract}
This paper deals with different types of operating system and also with the importance of the operating in a device (i.e. computers, mobile). Unfolding some of the questions like the need of different kinds of operating system and requirement of operating system within a device. We will also see the advantage of different types of operating system and disadvantages too. The paper will cover not only operating system for computers but also the systems which we use in our day to day life such as mobile phones (android) and the once which we use in our computers (windows, linux, etc).
\end{abstract}

Keywords - Windows, Android, Linux, Operating system, iOS, POSIX, DOS, Kernel, AOSP (Android Open Source Project), NT, Vista, System Libraries, Screensearch, VDD (Virtual Device Drivers), User Interface.

\section{INTRODUCTION}

The Operating system in a device can be seen as the bridge between the users need and the resources offered by the computer hardware. Operating system is a software and moreover it is a system software, it not only bridge the gap between the user and the computer hardware but also has many functions in the computer system such as managing computer memory, files, and protecting other system softwares. So, for performing all of these functions we have many operating system and in this paper I have discussed the prominent and most widely and currently using operating system.

\section{LITERATURE REVIEW}

The operating is responsible for managing various resources of the computer system such as storage devices, hardware resources, input/output devices, network resources, and other devices. For the personal computer, the most popular operating system is Dos and Windows, but others are available such as Linux. The most popular and widely using operating system in mobile is Android, iOS, Windows. So, in the paper we have compiled up different types of Operating System on the basis of usability and other facilities.

\section{CLASSIFICATION OF DIFFERENT TYPES OF OPERATING SYSTEM:}

Here we have done the classification on the basis of different kinds of operating system, widespread usability with different devices and also discuss the past and the present facilities of different operating system.

\subsection{Windows Operating system:}

Windows is a graphical or figure based operating system shellfor MS-DOS (Microsoft Disk Operating System) launched on November, 1985. Windows is an operating system released by keeping the primary focus on the increasing demands of the personal computer and graphical user interface. So, let's see different versions of the windows operating system. 


\section{International Journal of Engineering Applied Sciences and Technology, 2021 Vol. 6, Issue 2, ISSN No. 2455-2143, Pages 177-183 \\ Published Online June 2021 in IJEAST (http://www.ijeast.com)}

\subsubsection{Windows 3.x:}

This version of Microsoft Windows 3.0 and 3.1 is loaded with the features such as VDD ("Virtual Device Drivers") that helps to share random devices between multi functioned DOS applications. [6] This versions applications may execute in confinedor protected mode, which makes them available with number of (MB) megabytes of memory with no restriction to take part in the software virtual memory. The address space is same and do not changes for execution, where the segmented memory provide layers of protection. Windows 3.0 also implements some improvements to the user interface.

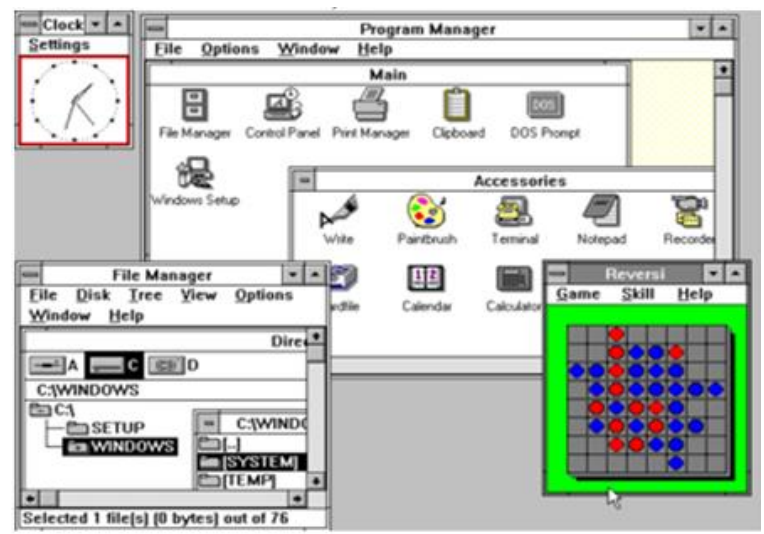

Fig 3.1.1

As from Fig. 3.1.1 We can see that there the Windows 3 is GUI based and more convenient for users as well as provide multitasking.

\subsubsection{Windows 9.x:}

On August 1995 Windows 95 was launched. Windows 95 is still based on MS-DOS, it is launched with access for local 4-bytes(32-bits) applications, attach and use hardware, preemptive scheduling, file names supportive till 255 characters, and offers higher stability over its previous versions. Windows 95 comes with a newly designed user interface, and introduced new start menu, task bar, and Windows Explorer shell.

\subsubsection{Windows NT:}

NT operating system was released and is more planned towards security, towards multi users capability and also with POSIX compatibility and developed on an extensible, kernel including preemptive scheduling and also gives support for multiprocessor architecture. [7] The kernel of Windows NT is altogether a different kernel from windows previous versions and is a hybrid kernel which was built by Windows and IBM. The Mach microkernel is the basis of the hybrid kernel of the Windows NT.

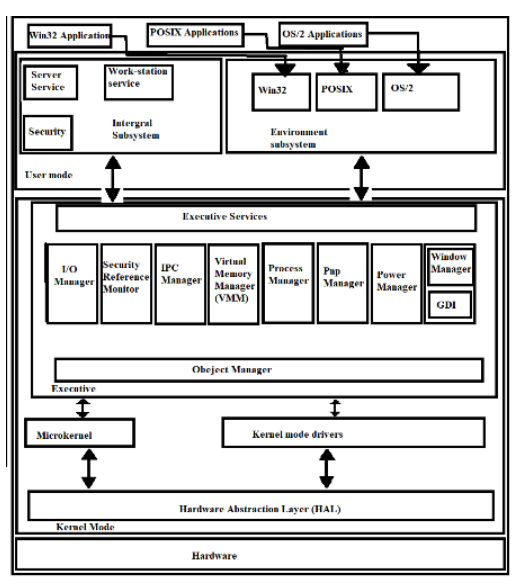

Fig · 3.1.3

From Fig. 3.1.3 We can see the flow chart of the Windows NT and here we can see POSIX which provide multiuser capability.

\subsubsection{Windows XP:}

Windows XP comes with altogether a new user interface(UI) which imbibes new Start menu and Windows Explorer, smooth running multimedia and network facilities, and XP arrived with different modes which are capable of providing stability with software that are used with the previous versions of the windows, and virtual assistance. Windows XP was very successful operating system as even after the release of windows successor and people find it easy to use.

\subsubsection{Windows Vista:}

Vista comes with new functions, such as new shell and user interface to notable technical changes, with a strong focus on security functionalities. It comes with different types editions, and moreover to make the system highly secure a stricter license agreement was there with Windows Vista.

\subsubsection{Windows 7:}

Windows 7 was launched with gradual uplift to the Windows line, comes up with certain features such as being stable with applications and hardware that is very stable with Windows vista. Windows 7 was loaded with number of features such as multi-touch support, a newly designed shell, revamped taskbar, HomeGroup which is home networking system. 


\section{International Journal of Engineering Applied Sciences and Technology, 2021 \\ Vol. 6, Issue 2, ISSN No. 2455-2143, Pages 177-183 \\ Published Online June 2021 in IJEAST (http://www.ijeast.com)}

Windows 7 is popular due to its minimal system necessities.

\subsubsection{Windows 8:}

Windows 8 was released with altogether a new and different approach towards user interface by making changes in the start screen, which includes large tiles that are more useful for touch interactions which permit for the present continually updated information, and arrived with a fairly new sets of applications which are designed keeping the touch based devices in priority. Windows 8 is loaded with features such as cloud facilities and other online platforms such as Microsoft OneDrive etc. It is further upgraded to Windows RT for use on devices that utilize the ARM architecture.

\subsubsection{Windows 10:}

Windows 10 comes up reinvented start menu and capability to execute windows store application inside the windows on the desktop in spite of the full screen. All new Windows 10 is loaded with bucket full of new features such as Multiple desktop options which let us to move some of our Tabs to virtual desktop to keep them aside. Similar to Siri and Google Now, we have Cortana as a virtual assistant in Windows 10, we also have a tablet mode in Windows 10 which enhances the user experience numbers of revised new features.

3.1.9. Classification of different versions of Windows on the basis of usability and Popularity:

Windows Operating system is very famous operating system and also very dominating operating system in the market from starting of the Windows to present day and continuously evolving operating system. [3] The few Windows operating system which have perform outstanding for the users and gained much popularity are Windows XP, Window 95, Windows 10 , Windows 7 and Windows 8 . Windows 95 is also one of the most popular and widely used Windows Operating System and help Windows and Users to have altogether different experience of Windows Operating System for the basic CUI users and also presented very user friendly GUI. [3] Windows XP was able to make its presence even after the release of the Windows Vista and Windows 8. Windows 10 brought all the major features of Windows into one shed and also become one of the most widely using Windows Operating system.

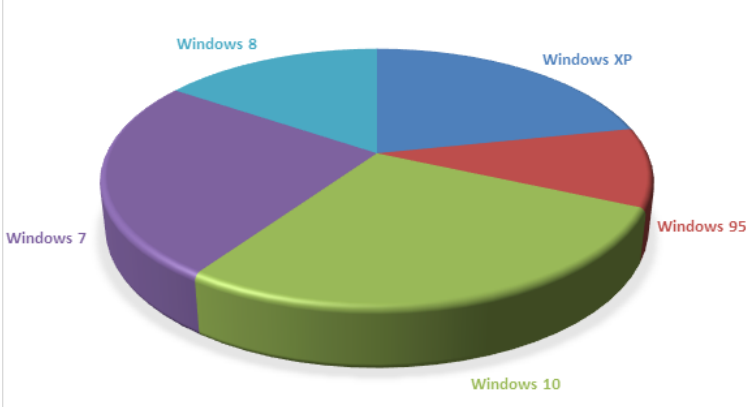

Fig. 3.1.9

\subsection{Linux Operating System:}

Linux is one of the open source operating system which is based on linux Kernel. [9] Linux was launched in September 1991 and developed by Linus Torvalds and the developing methods involved are KernelCare, dpkg, GNOME software. Let's see features of linux Operating system. Fig.3.2 represents the basic user interface of Linux Operating System.

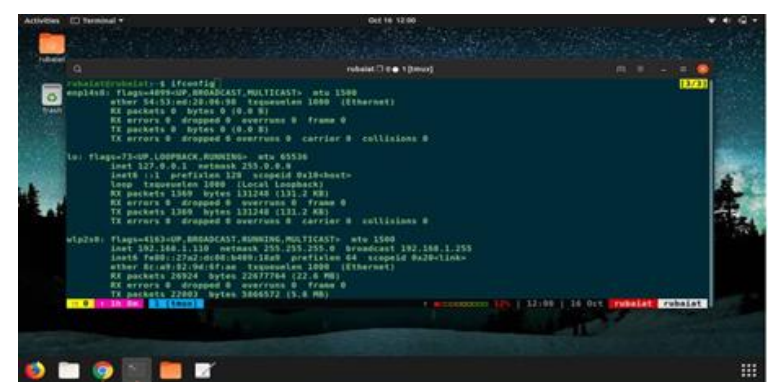

Fig. 3.2

\subsubsection{Features of Linux:}

Linux is an operating system which can be used on different devices in the same way and in this way it implement portability. Linux kernel and its apps can works on different kinds of hardware. Linux Operating system source code is freely available for modifications. [4] So, we can say that Linux is continuous developing Operating system. Linux has the capability of running multiple programs simultaneously. [8] So, Linux is multiprogramming operating system. Linux gives access of resources like memory, RAM, and other programs to multiple user at the same time which means that Linux is multiuser operating system. Security is the one of the key feature of Linux operating system such password prevention, controlling the access of certain files, encryption/decryption of data. Linux provide a special interpreter program so that can be utilize in execution of the commands of operating system. As android is based on linux and most of the 


\section{International Journal of Engineering Applied Sciences and Technology, 2021 \\ Vol. 6, Issue 2, ISSN No. 2455-2143, Pages 177-183 \\ Published Online June 2021 in IJEAST (http://www.ijeast.com)}

smartphones are based on android. So, it is one of the largest installed base of all general purpose OS which shows the reliability of Linux operating system and usability in wide range of hardware.

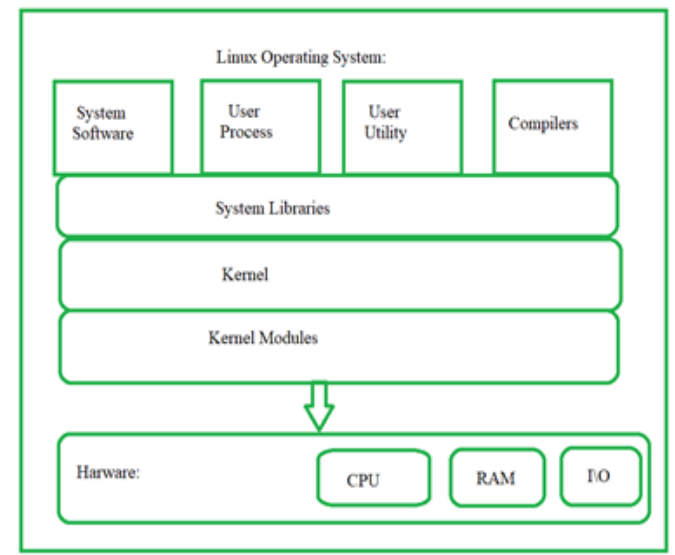

Fig. 3.2.1

Fig. 3.2.1 shows the basic structure of the Linux Operating system which shows that the user is given higher priority over system libraries and kernel communication with the user.

\subsubsection{Components of Linux: \\ Kernel:}

[10]Kernel is involved in all the important activities of this Operating System. In linux Kernel is divided into various unit which communicates with the hardware directly. Kernel is core component of Linux Operating system.

\section{पLLinux System Libraries:}

The application program uses the kernel facilities with the help of linux system libraries. The system libraries are responsible for the implementation of the features of the operating system.

\subsection{Android Operating System:}

Android is basically Mobile Operating System and it also used to bridge the gap between user and hardware, Android can be used in number of hardware firstly it is launched with a semi-touch mobile and later on android operating system is used in touch screen devices such as smartphones, tablets, etc. Android is first released in 2008. Android is free and open source software, Android source code is known as (AOSP) Android Open Source project (AOSP). There are different android versions which provide different features as per there evolution with time. So, let's take a look upon them starting with Android Jellybean (4.1 and 4.3):

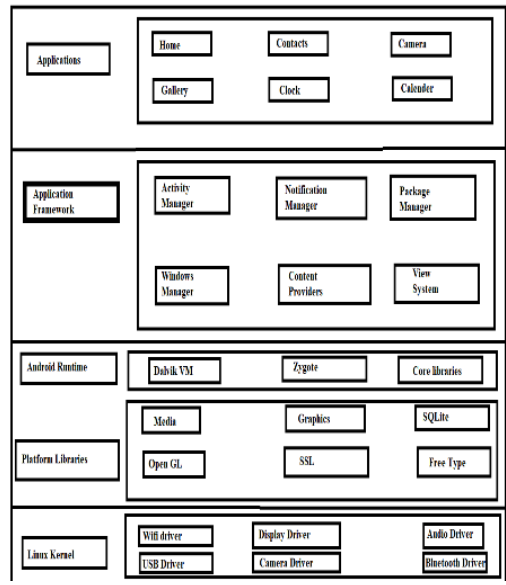

Fig 3.3

Fig.3.3 shows the basic structure of Android Operating system with different stages such as Application stage where the users access the information from the system. Application Framework is the area which manages the Application stage. As, we know from the introduction that Android is open source So, it is based on linux Kernel which also open source and updatable.[1]

Android version JellyBean(4.1 and 4.3): JellyBean comes up with the Google Now the amazing intelligence system. Jellybean provide impressive notification, in-built voice search system. [2]Android Jellybean comes up with multiuser facility and in tablets not more than one user. Jellybean displays the search results with card based system which attempt to answer questions directly.

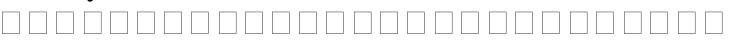

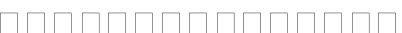

\section{$\square$ Android version Kitkat (4.4):}

Kitkat comes with new features and some of them used for the first time such as "OK Google" but in Kitkat, this voice recognition system work well only when mobile screen was on and inside the Google app or at home screen. Kitkat was Google's move to overtake the front panel of the home screen to implement its facilities.

\section{Android version Lollipop(5.0 and 5.1):}

Android Lollipop brought all together new looks that extended across all of Android, its apps and even other Google products. Also the "OK GOOGLE" facility is available on the lock screen and with occurrence all notifications such as email, messages 


\section{International Journal of Engineering Applied Sciences and Technology, 2021 Vol. 6, Issue 2, ISSN No. 2455-2143, Pages 177-183 \\ Published Online June 2021 in IJEAST (http://www.ijeast.com)}

and also till the release of Lollipop the card based recent apps become a core part in android.

\section{Android version Marshmallow (6.0):}

The attractive part of the Marshmallow was the on screen search facility known as "Now On Tap". Marshmallow did introduce some features which impact greatly, although, having stronger application permissions, includes fingerprint support, and support for C-Type USBs.

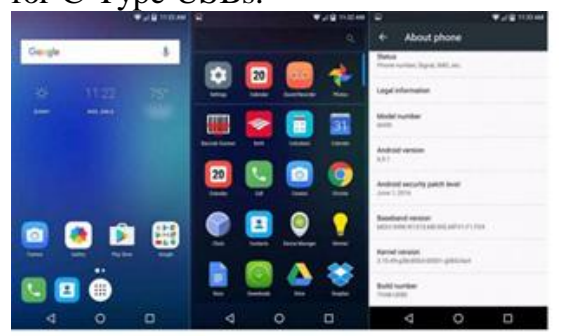

Fig. 3.3.1

Fig. 3.3.1 shows the impressive User interface of the Android Marshmallow and the altogether new feature of Google that is "Now On Top" search bar that opens new window for search engine.

$\square$ Android version Nougat(7.0 and 7.1): Nougat comes with split-screen mode, a apps packing into one system and features like notifications management, and much more like data saving schemes. Nougat implement small and creative features such as Alt-Tab for snapping between applications.

\section{Android version Oreo (8.0 and 8.1):}

Oreo comes with the features like a picture in picture mode, Oreo have notifications managing options like snoozing the notifications, and channels of notifications which provide control over different app alerts. Oreo helps Google in managing "Android" and "Chrome OS" and enhances the experience of using android applications on Chromebooks.

\section{Android version $\operatorname{Pie}(9.0$ and 9.1):}

Pie comes with features such as "gesture" and "button" exploration system. [11]Pie comes with different other features such as, "Digital Wellbeing Dashboard controls", facilities such as "self reply" system for managing the notifications, and improved intelligent system managing the screen brightness and the power of the system.

\section{Android version 10:}

Android 10 comes with number of features such as redesign interface for "Android Gestures" such that it comes with the three button navigations or user can choose navigation via swiping i.e. without buttons. [12] Android 10 is faster and has improvement under which permission system is there which benefits the user by giving control of how and when apps will be able to access the location.[5] Also improved GUI that includes a wide dark theme and features like focus mode which helps user not to get away with distraction.

\section{$\square$ Android version 11:}

Android 11 comes with number of features such as improved privacy systems that helps user to control certain permissions that arrived in Android 10 such as permissions of location, camera, microphone become limited to, single use basis. Android 11 comes up with ability which do not allow an application to access or see details of another application on the same system which was not there in early Android systems and this feature helps in prevent the information. Android 11 introduced Bubble

that allows user to pop out the conversations out into floating windows which appears on the top of other program of the user.
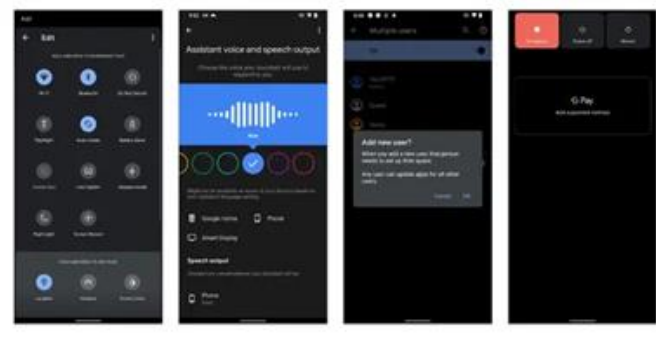

Fig.3.3.2

Fig. 3.3.2 shows the user interface of the Android 11 and the difference of the voice recognition in android 11 and previous android Operating system.

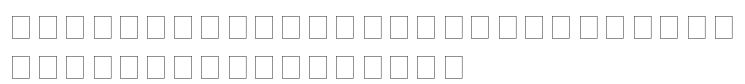

IV. COMPARISON TABLE 


\section{International Journal of Engineering Applied Sciences and Technology, 2021 \\ Vol. 6, Issue 2, ISSN No. 2455-2143, Pages 177-183 \\ Published Online June 2021 in IJEAST (http://www.ijeast.com)}

\begin{tabular}{|c|c|c|c|}
\hline $\begin{array}{l}\text { Operating } \\
\text { system }\end{array}$ & $\begin{array}{l}\text { Availabi } \\
\text { lity } \\
\text { (Source } \\
\text { code) }\end{array}$ & $\begin{array}{l}\text { User } \\
\text { Modificati } \\
\text { on }\end{array}$ & Usability \\
\hline Windows OS & $\begin{array}{l}\text { Not } \\
\text { freely } \\
\text { Availabl } \\
\quad \text { e } \\
\\
\text { Freely } \\
\text { Availabl } \\
\quad \text { e }\end{array}$ & $\begin{array}{l}\text { User } \\
\text { cannot } \\
\text { modify in } \\
\text { OS } \\
\text { independe } \\
\text { ntly } \\
\text { User can } \\
\text { easily } \\
\text { Modify } \\
\text { the OS as } \\
\text { source } \\
\text { code } \\
\text { freely } \\
\text { available. }\end{array}$ & $\begin{array}{l}\text { Windows } \\
\text { OS } \\
\text { provide } \\
\text { ease of } \\
\text { use and } \\
\text { nice GUI } \\
\text { Widely } \\
\text { used by } \\
\text { program } \\
\text { mers and } \\
\text { gained } \\
\text { much } \\
\text { attention } \\
\text { in few } \\
\text { years. }\end{array}$ \\
\hline Android OS & $\begin{array}{l}\text { Freely } \\
\text { Availabl } \\
\quad \text { e }\end{array}$ & $\begin{array}{l}\text { Android is } \\
\text { source } \\
\text { code } \\
\text { freely } \\
\text { available } \\
\text { OS. So, } \\
\text { users can } \\
\text { easily } \\
\text { modify it. }\end{array}$ & $\begin{array}{l}\text { Android } \\
\text { have the } \\
\text { largest } \\
\text { number } \\
\text { of users in } \\
\text { mobile } \\
\text { OS. }\end{array}$ \\
\hline
\end{tabular}

\section{FUTURE SCOPE:}

As, the technology is evolving day by day and there is continuous evolution of the hardware and software which demands for a strong software that can manage all the devices, system resources, maintain synchronization in the system, and makes the best of the use of the available hardware and software to the user. So, all these features are the primary role of the Operating system and OS can provide more functions than the primary. This tells about the reliability and requirement of Operating system in the upcoming future and as, the operating system creates an environment for user to utilize the hardware that is possible due to the operating system.

\section{CONCLUSION:}

As, from the above paper it is clear that the in present scenario the operating system is not only performing the primary operations but delivering more than that and the operating system which is making the best use of the hardware and providing more functionalities is sustained in the market and the demand of the users is also increasing very rapidly that requires a strong and fast operating system. As far as my evaluation Linux Kernel and Android based Operating system is making a cutting edge competition in the market, not only this by every passing year they are new users are heavily using the Operating system and further they are continuously evolving operating system. So, this Operating system is preferable over others as per my papers and study.

\section{REFERENCES}

[1] Kosmach J, Neff R, Sherwood G, et al. Introduction to OpenCORE Audio Components Used in the Android Platform[C]//Audio Engineering Society Conference: $34^{\text {th }}$ International Conference:New Trends in Audio for Mobile and Handheld Devices. Audio Engineering Society, 2008.

[2] Zhaojian M. Android-based Mobile Interlligent Application Development-The Development and Implementation of the Game Lianliankan[D]. Beijing University of Posts and Telecommunication, 2010.

[3] Gerard O'Regan. "A Brief History of Computing”, Springer Science and Business Media LLC, 2021

[4] Brandon LeBlanc, "Windows 8-40 Million Licenses Sold", Available at:,[online]M

Available:

http://blogs.windows.com/windows/b/bloggingwindo ws/archive/2012/11/27/windows-8-40-million-

licenses-sold.aspx.

[5] M. Pangaria, V. Shrivastava and P. Soni, "Compromising Windows 8 metasploit's exploit", Technology, vol. 7, no.2, pp. 119-123, 2012.

[6] LOVE, ROBERT. Linux Kernel Development[M]. New York, New York, USA: MacMillan Computer PUB,(2005).

[7] Keir Thomas. Beginning Ubuntu Linux[M]. New York, New York, USA: Springer-Verlag New York Inc,(2005).

[8] M. Shameek, G. Digbijay, K.Sayak and B. Juin "Windows 10", International Journal of Engineering Technology \& Management Research, pp. 59-64, 2015. 
[9] Android open Source Project. Android Security . Overveiw:http://source.android.com/devices/tech/sec urity/index.html.

[10] Jing-Ming, S.H.I.U. and Yasumto, M., 2016. Benefitting from Contributions to the Android Open Source Community. Annals of Business Administrative Sciences, 10(2), pp.557-562.
[11] Moontechnolabs/android-60-marshmallowfeatures-whats-new

[12] "Android 4.1.1 Nexus 7 Update" . GSMArena.com. July11, 2012. Retrieved February 26, 2013", Android 4.1.2. rolling out for Nexus 7". The Verge. October 9,2012. Retrieved October 9, 2012. 